\section{Case Reports in Neurology}

Case Rep Neurol 2020;12:472-481

DOI: $10.1159 / 000510517$

Published online: December 11, 2020
(C) 2020 The Author(s)

Published by S. Karger AG, Basel 2 OPEN

www.karger.com/crn

This article is licensed under the Creative Commons Attribution-NonCommercial 4.0 International License (CC BY-NC) (http://www.karger.com/Services/OpenAccessLicense). Usage and distribution for commercial purposes requires written permission.

\title{
Psychogenic Seizure Imitating Narcolepsy
}

\author{
Galina M. Diukova ${ }^{a}$ Sergey A. Makarov ${ }^{b}$ Valery L. Golubev ${ }^{b}$ \\ Ruslana R. Tyutina ${ }^{a, b} \quad$ Daniil A. Degterev ${ }^{a}$ Alexey B. Danilov ${ }^{b}$ \\ aNeurological Department, Moscow Clinical Research Center, Moscow, Russia; \\ ${ }^{b}$ Department of Nervous Disease, I.M. Sechenov First Moscow State Medical University \\ (Sechenov University), Moscow, Russia
}

\section{Keywords}

Functional neurological disorders · Pseudonarcolepsy · Psychogenic non-epileptic seizures

\begin{abstract}
Psychogenic or functional neurological disorders (FND) often occur in the practice of a neurologist. Diagnosis of FND usually causes significant difficulties. Among FND, psychogenic non-epileptic seizures (PNES) comprise around $40 \%$ cases. Sometimes it is necessary to differentiate PNES from narcolepsy. We describe a 55-year-old man with frequent brief and sudden sleep-like attacks in combination with nocturnal sleep disturbance. During attacks he was unresponsive, snoring but maintained posture. He resisted passive eye opening but with rolling eyes. The patient was confused on waking. In the interictal period, there were FND signs including give-way weakness of the left hand, typical functional "leg-dragging" gait, mistake in the finger-to-nose test. Video-electroencephalogram monitoring did not detect specific epileptic activity or sleep pattern during the attacks. Polysomnography showed multiple waking episodes during the night, but no typical pattern of narcolepsy was found in the multiple sleep latency test. The patient had frequent urgent hospitalizations due to different diseases and numerous invasive procedures. Six month later, the patient obtained state related disability financial benefit, after which hospitalizations in various hospitals continued, and PNES became shorter and less pronounced.




\section{Case Reports in Neurology}

Case Rep Neurol 2020;12:472-481

\begin{tabular}{l|l}
\hline DOI: 10.1159/000510517 & (c) 2020 The Author(s). Published by S. Karger AG, Basel
\end{tabular} www.karger.com/crn

Diukova et al.: Psychogenic Seizure Imitating Narcolepsy

\section{Introduction}

Narcolepsy is a neurological disease that is manifesting as difficulty with maintaining continuous wake and sleep. The cardinal signs of narcolepsy are daytime sleepiness, rapid-eye movement (REM), sleep dissociation (cataplexy, hypnagogic hallucinations, sleep paralysis), and disrupted nighttime sleep [1]. The diagnosis of narcolepsy is often delayed, with an average time from symptoms onset to diagnosis of 5-15 years. Errors in the diagnosis of patients with narcolepsy reach up to $46 \%$ [2].

The behavioral sleep without electroencephalogram (EEG) sleep patterns is referred to in the literature by the term "pseudo-sleep" or "pseudonarcolepsy" [3-5].

This article presents the case of a patient suffering from acute daytime sleep-like attacks and nightly sleep disturbances, which required differential diagnosis with narcolepsy.

\section{Case Presentation}

Patient Z., a 55-year-old man, is a college teacher. He presented with sudden attacks of "falling asleep" lasting 5-7 min, occurring up to 12 times a day with no specific attack triggers.

The patient reported sleep disturbance consisting of frequent nocturnal awakenings and unrefreshing sleep. As a result of the "falling asleep" attacks, he reported being unable to leave the house unaccompanied and usually visited the doctor with his 72-year-old mother. He had not been able to work for 5 months due to these attacks.

\section{Family History}

He was married and had a 23-year-old daughter, who had been suffering from epilepsy since she was seven.

\section{Medical History}

He had metabolic syndrome with a body mass index of 36, diabetes mellitus type 2 for the last 3 years (fasting glucose level from 5.8 to $8 \mathrm{mmol} / \mathrm{L}$ ), and essential hypertension for 5 years. He also had urinary stone disease and ischemic heart disease with frequent supraventricular extrasystoles.

The "sleep" attacks began 1 year previously after stressful interactions with his daughter. He reported that attacks begin with a feeling that "the eyes become heavy and sand appears in the eyes" and, according to witnesses, the patient "shuts down." All attempts to wake him during the attack were unsuccessful, and he was amnestic for the attack.

The patient was examined in the neurology department. In the daytime, sleep attacks were observed (shown in the online suppl. Video 1; for all online suppl. material, see www.karger.com/doi/10.1159/000510517). Attacks occurred while lying or sitting, starting with a gradual head fall, slow lowering to the side, but without falling, loss of connection with the environment, and lack of response to external stimuli. During the attack, there was snoring. His eyes were closed, with resistance to attempts to passively open them, and rolling eyes when they were opened (shown in Fig. 1 and online suppl. Video 2). He had peculiar movements of the hands and upper body, which resembled a myoclonic jerk (shown in Fig. 2). In the attacks, muscle tone was lowered, but with tonic spasms of the limbs and facial grimacing at the time of awakening (shown in Fig. 3). After "awakening", confusion was noted, lasting about 30-40 s (shown in Fig. 4), during which the patient looks around as if looking for

\section{Karger's}




\section{Case Reports in Neurology}

Case Rep Neurol 2020;12:472-481

\begin{tabular}{l|l}
\hline DOI: 10.1159/000510517 & (c) 2020 The Author(s). Published by S. Karger AG, Basel \\
\hline
\end{tabular} www.karger.com/crn

Diukova et al.: Psychogenic Seizure Imitating Narcolepsy

something. The patient ignores the doctor's questions and does not follow the instructions. Neurological assessment indicated "give-way" weakness in the hands, greater on the left, a positive sternocleidomastoid (SCM) muscle test on the left side [6], typical functional "legdragging" gait, non-anatomical disturbance of sensation.

\section{4-Hour Video-EEG Monitoring}

Eight episodes were recorded, all with an identical clinical picture and duration of 5-7 min. In some cases, the patient was able to mark the "event" with the button when he "felt sleepy" or "fell asleep" (during the attack). At the time of the attack, the EEG recorded a normal awake pattern with no epileptic activity or evidence of a sleep pattern.

Polysomnography (PSG) was conducted in accordance with generally accepted methodology [7]. The duration of night sleep (7.4 h) was within normal limits. The structure of sleep was changed due to an increase in the number of awakenings (40) and duration of wakefulness during sleep (41 min, normally <30). Mild obstructive apnea/hypopnea syndrome was diagnosed on the basis of apneic/hypopneic episodes $(10.3$ episodes/h, normally $<5)$. The mean saturation was $\mathrm{O}_{2}-93 \%$.

\section{Multiple Sleep Latency Test Results}

Characteristic signs for narcolepsy were not revealed. Episodes of early onset of rapid eye movements (REM) sleep occurred zero times out of five occasions measured. Average time to fall asleep is $16.4 \mathrm{~min}$ (normally $>8 \mathrm{~min}$ ) [8].

\section{4-Hour ECG Holter Monitoring}

Cardiac rhythm disturbance (supraventricular extrasystoles) were periodically detected unrelated to the attacks.

\section{MRI of the Brain}

Multiple single non-specific white matter T2 hyperintense lesions in white matter around the ventricles of the brain were detected (Fazekas grade 1).

A review of his medical records found that within 1.5 years, the patient was hospitalized 12 times with various conditions, 8 times "urgently." On no occasion was a new diagnosis or exacerbation of a pathophysiological diagnosis proven. In total, doctors made more than 30 different somatic diagnoses, including "exacerbation" of pre-existing diseases (diabetes mellitus, coronary heart disease, urolithiasis, varicose veins, otitis media) and the appearance of new diseases (cluster headache and trigeminal neuralgia, psychogenic non-epileptic seizures [PNES], etc.).

\section{Follow-Up History (8 Months after Neurological Assessment)}

The patient was hospitalized 5 further times in different clinics for emergency reasons: ENT ("acute otitis"), psychiatry (where "unspecified attacks" were diagnosed), hematology with suspected polycythemia (with bone marrow biopsy), gastroenterology (in relation to "gastrointestinal bleeding"). During treatment in the endocrinology clinic, the treating physician suspected a fabricated symptom when he found hyperglycemia (up to $22 \mathrm{mmol} / \mathrm{L}$ ) with adequate insulin therapy.

Finally, the patient managed to get disability, after which hospitalizations in various hospitals continued, but PNES became shorter and less pronounced (online suppl. Video 3).

\section{Karger'=}




\section{Case Reports in Neurology}

Case Rep Neurol 2020;12:472-481

\begin{tabular}{l|l}
\hline DOI: 10.1159/000510517 & (c) 2020 The Author(s). Published by S. Karger AG, Basel
\end{tabular} www.karger.com/crn

Diukova et al.: Psychogenic Seizure Imitating Narcolepsy

\section{Discussion}

Psychogenic seizures are the most common manifestation of functional neurological disorders. They can mimic both epileptic and nonepileptic attacks. The peculiarity of the patient we describe is that sleep-like attacks and nocturnal sleep disturbance appeared in an older man, complicated by many somatic diseases, which could have potentially be contributing to the cause of the attacks themselves. A differential diagnosis was initially considered of epilepsy, arrhythmias, sleep disorders (narcolepsy and sleep apnea syndrome), and mental disorders.

1 Short duration, complete unresponsiveness and peculiar hand movements in the attack and postictal confusion required a differential diagnosis with epileptic seizures. When performing video-EEG monitoring, several typical "shutdown" episodes without EEG patterns characteristic of epilepsy were recorded. Therefore, it could be concluded that paroxysms were not epileptic in nature.

2 Heart rhythm disturbances are a common cause of loss of consciousness in older people. In this case, although supraventricular extrasystoles were recorded, they did not correlate with the "sleep" attacks.

3 The patient had subjective and objective sleep disturbance. Excess daytime sleepiness syndrome due to sleep deprivation and sleep apnea syndrome could have contributed. PSG did not shown decreased total sleep time, but there was evidence of mild sleep apnea.

4 Sudden brief sleep-like attacks, frequent awakenings in a night's sleep, suggested a possible diagnosis of narcolepsy. However, onset of attacks in an older man, PSG results (no decrease in the latency of the REM sleep stage), normal MSLT, EEG at the time of "sleep" attack (no sleep pattern registered) all indicated that narcolepsy was not present.

Thus, it was shown that the aforementioned attacks do not correspond to any of these variants of organic paroxysmal conditions.

For a positive diagnosis of the psychogenic etiology of attacks, i.e., PNES, it is necessary to identify the specific features of psychogenic or functional neurological disorders [9]. Resistance to passive opening of the eyelid and rolling up of the eyeballs upwards are regarded as highly reliable signs of PNES $[3,10,11]$. In addition, the high frequency of attacks, their long duration, and their occurrence at the doctor's appointment strongly suggest PNES, in contrast to epileptic events [12]. The medical history, semiology of PNES, and recording of attacks on video EEG with lack of epileptic activity before, during, and after the attack allowed us to qualify these seizures as "documented" PNES [13]. During a neurological examination of the patient, clear functional neurological signs were revealed. These are functional paresis and gait (dragging leg). Thus, the analysis of the main presented symptoms of the patient suggested a psychogenic etiology of both paroxysms and interictal symptoms.

The frequency of Factitious Disorder in general practice is on average 1.3\% [14]. There is a view that Factitious Disorder is a more severe form of functional neurological disorder [15]. DSM-5 Factitious Disorder is under the heading "Somatic Symptoms and Related Disorders" together with Conversion (Functional Neurological Symptom) Disorder, although Factitious Disorder clearly involves willful simulation of symptoms, whereas Functional Neurological Disorder describes genuinely experienced symptoms [16]. Neurological symptoms are common in patients with factitious disorder. Among them, PNES and pseudoepileptic status are common $[17,18]$.

This patient presented with exaggeration of symptoms, concealment of information about previous visits for medical help, elaborate stories about previous hospitalizations, where the

\section{Karger'=}




\section{Case Reports in Neurology}

\begin{tabular}{l|l}
\hline Case Rep Neurol 2020;12:472-481 \\
\hline DOI: 10.1159/000510517 & $\begin{array}{l}\text { @ 2020 The Author(s). Published by S. Karger AG, Basel } \\
\text { www.karger.com/crn }\end{array}$ \\
\hline Diukova et al: Psychogenic Seizure Imitating Narcolepsy
\end{tabular}

patient is presented as a victim ("the whole bathroom was filled with blood"), repeated multiple hospitalizations, functional neurological disorders, and possible artificially induced symptoms (e.g., hyperglycemia). After receiving state-related financial disability compensation, both urgent hospitalizations and seizures persisted. These facts made it possible to suggest a diagnosis of Factitious Disorder.

This publication also presents the first description of a pseudo-narcoleptic attack of "falling asleep," which required differential diagnosis with narcolepsy.

\section{Statement of Ethics}

The patient has given his written informed consent to publish this case, including images and online supplementary videos.

\section{Conflict of Interest Statement}

The authors declare that the research was conducted in the absence of any commercial or financial relationships that could be construed as a potential conflict of interest.

\section{Funding Sources}

The authors received no funding for the publication of the manuscript.

\section{Author Contributions}

G.M.D., S.A.M., V.L.G., R.R.T., D.A.D., and A.B.D. contributed to the manuscript development, rationale, manuscript images and video, and patient management. All authors read and approved the final manuscript.

\section{References}

1 Ruoff C, Rye D. The ICSD-3 and DSM-5 guidelines for diagnosing narcolepsy: clinical relevance and practicality. Curr Med Res Opin. 2016 Oct;32(10):1611-22.

2 Dunne L, Patel P, Maschauer EL, Morrison I, Riha RL. Misdiagnosis of narcolepsy. Sleep Breath. 2016 Dec;20(4):1277-84.

3 Benbadis SR, Lancman ME, King LM, Swanson SJ. Preictal pseudosleep: a new finding in psychogenic seizures. Neurology. 1996 Jul;47(1):63-7.

4 Hicks JA, Shapiro CM. Pseudo-narcolepsy: case report. J Psychiatry Neurosci. 1999 Sep;24(4):348-50.

5 Hvidsten S, Bates G. Pseudonarcolepsy in an 11-year-old boy. Clin Child Psychol Psychiatry. 2008 Oct;13(4):585-91.

6 Diukova G, Stolajrova A, Vein A. Sternocleidomastoid (SCM) muscle test in patients with hysterical and organic paresis. J Neurol Sci. 2001;187(suppl:108).

7 Kushida CA, Littner MR, Morgenthaler T, Alessi CA, Bailey D, Coleman J Jr, et al. Practice parameters for the indications for polysomnography and related procedures: an update for 2005. Sleep. 2005 Apr;28(4):499521.

8 Aldrich MS, Chervin RD, Malow BA. Value of the multiple sleep latency test (MSLT) for the diagnosis of narcolepsy. Sleep. 1997 Aug;20(8):620-9.

\section{Karger'=}




\section{Case Reports in Neurology}

9 Stone J, Reuber M, Carson A. Functional symptoms in neurology: mimics and chameleons. Pract Neurol. 2013 Apr;13(2):104-13.

10 DeToledo JC, Ramsay RE. Patterns of involvement of facial muscles during epileptic and nonepileptic events: review of 654 events. Neurology. 1996 Sep;47(3):621-5.

11 Lafrance WC, Ranieri R, Blum AS. Nonepileptic seizures - objective phenomena, 2016, p. 297-304. https://doi.org/https://doi.org/10.1016/B978-0-12-801772-2.00026-6.

12 Gröppel G, Pataraia E, Olbrich A, Bacher J, Leutmezer F, Aull S, et al. Clinical symptoms in psychogenic seizures. Wien Klin Wochenschr. 1999 Jun;111(12):469-75.

13 LaFrance WC Jr, Baker GA, Duncan R, Goldstein LH, Reuber M. Minimum requirements for the diagnosis of psychogenic nonepileptic seizures: a staged approach: a report from the International League Against Epilepsy Nonepileptic Seizures Task Force. Epilepsia. 2013 Nov;54(11):2005-18.

14 Fliege H, Grimm A, Eckhardt-Henn A, Gieler U, Martin K, Klapp BF. Frequency of ICD-10 factitious disorder: survey of senior hospital consultants and physicians in private practice. Psychosomatics. 2007 JanFeb;48(1):60-4.

15 Reuber M, Pukrop R, Mitchell AJ, Bauer J, Elger CE. Clinical significance of recurrent psychogenic nonepileptic seizure status. J Neurol. 2003 Nov;250(11):1355-62.

16 American Psychiatric Association. Diagnostic and Statistical Manual of Mental Disorders. American Psychiatric Association; 2013. https://doi.org/10.1176/appi.books. 9780890425596.

17 Jones JR, Horrocks FA. Fictitious epilepsy associated with amnesia. Br J Psychiatry. 1987 Feb;150(2):257-8.

18 Bauer M, Boegner F. Neurological syndromes in factitious disorder. J Nerv Ment Dis. 1996 May;184(5):2818. 
Case Reports in Neurology

\begin{tabular}{l|l}
\hline Case Rep Neurol 2020;12:472-481 \\
\hline DOI: 10.1159/000510517 & $\begin{array}{l}\text { @ 2020 The Author(s). Published by S. Karger AG, Basel } \\
\text { www.karger.com/crn }\end{array}$ \\
\hline
\end{tabular}

Diukova et al.: Psychogenic Seizure Imitating Narcolepsy

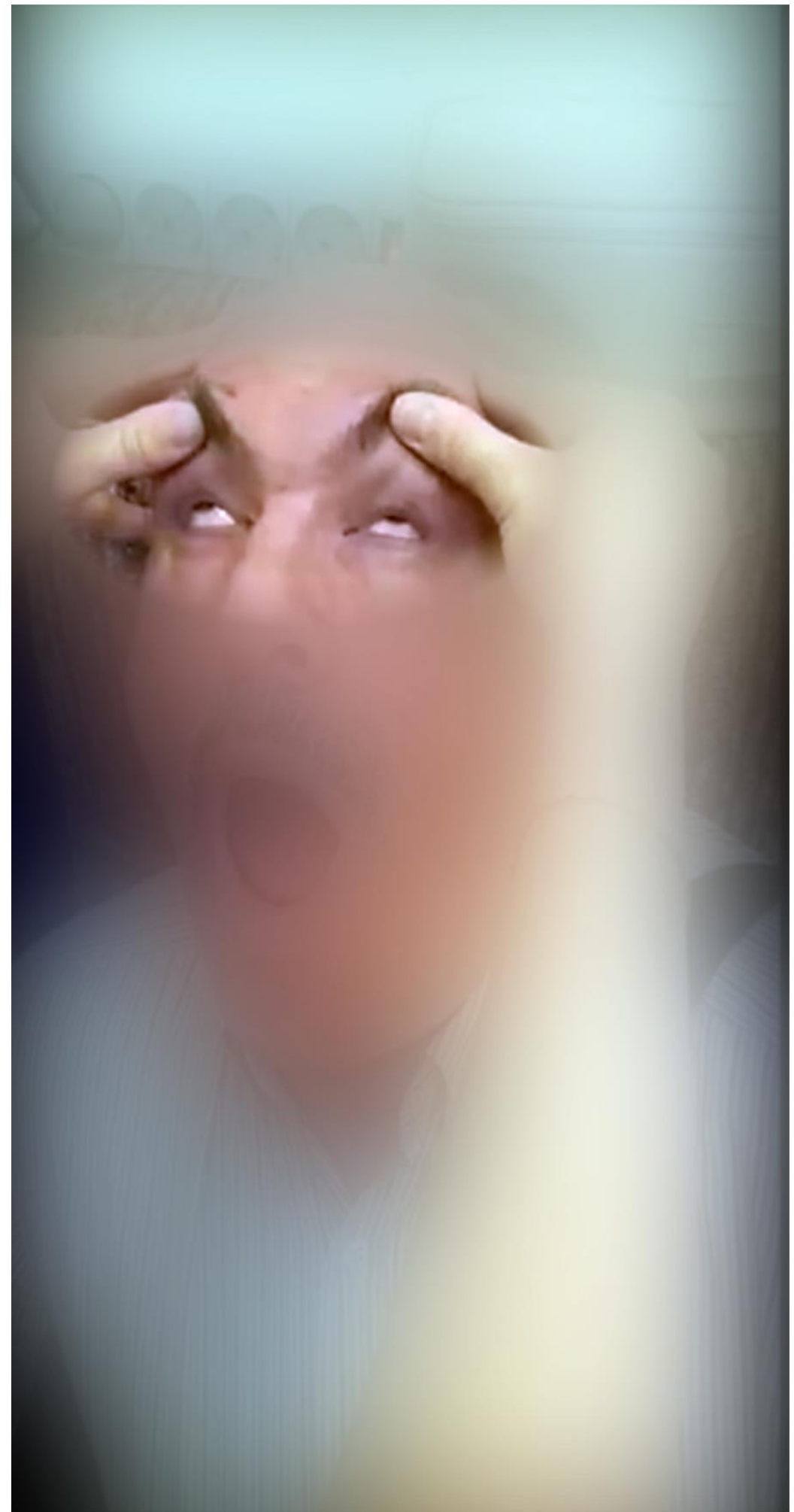

Fig. 1. Sleep attack. The patient sits with his eyes closed and his mouth open. When the doctor tries to open the patient's eyes, the patient resists and eye rolling is visible.

\section{Karger's}


Case Reports in Neurology
Case Rep Neurol 2020;12:472-481 DOI: 10.1159/000510517

(c) The Author(s). Published by S. Karger AG, Basel Diukova et al: Psychogenic Seizure Imitating Narcolepsy

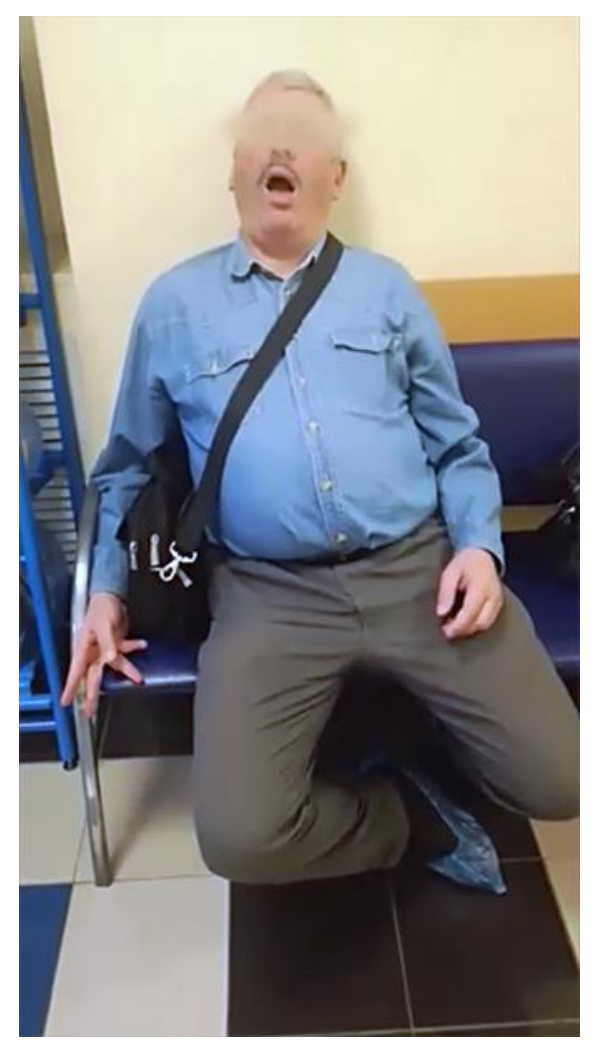

Fig. 2. Nonspecific movement of arms during attack. 
Case Reports in Neurology
Case Rep Neurol 2020;12:472-481 DOI: 10.1159/000510517

(c) The Author(s). Published by S. Karger AG, Basel Diukova et al.: Psychogenic Seizure Imitating Narcolepsy

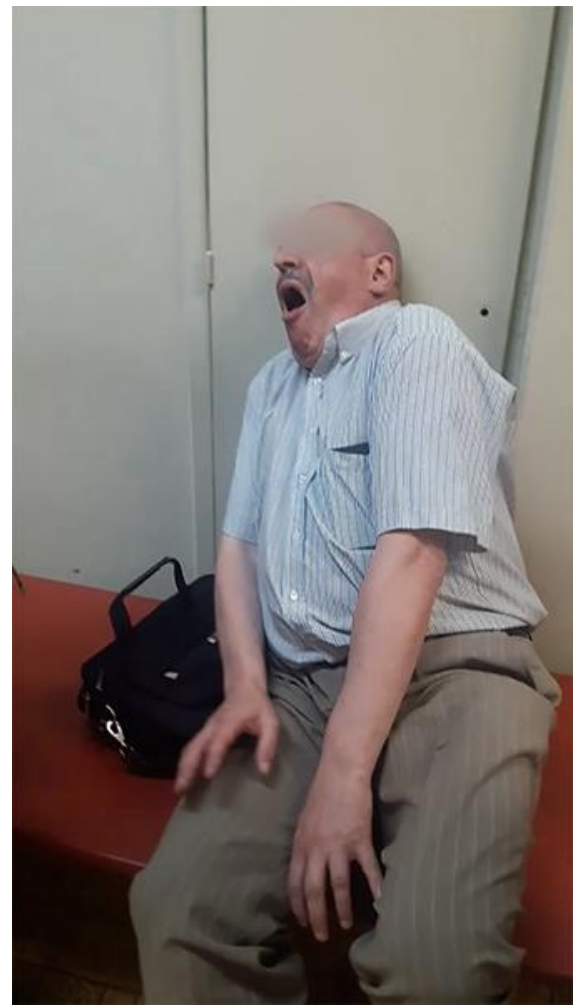

Fig. 3. Awaking: grimace, tonic spasm in arms. 
Case Reports in Neurology \begin{tabular}{l|c|}
\hline Case Rep Neurol 2020;12:472-481 \\
\hline DOI: $10.1159 / 000510517$ & $\odot$
\end{tabular}

(c) 2020 The Author(s). Published by S. Karger AG, Basel www.karger.com/crn

Diukova et al.: Psychogenic Seizure Imitating Narcolepsy
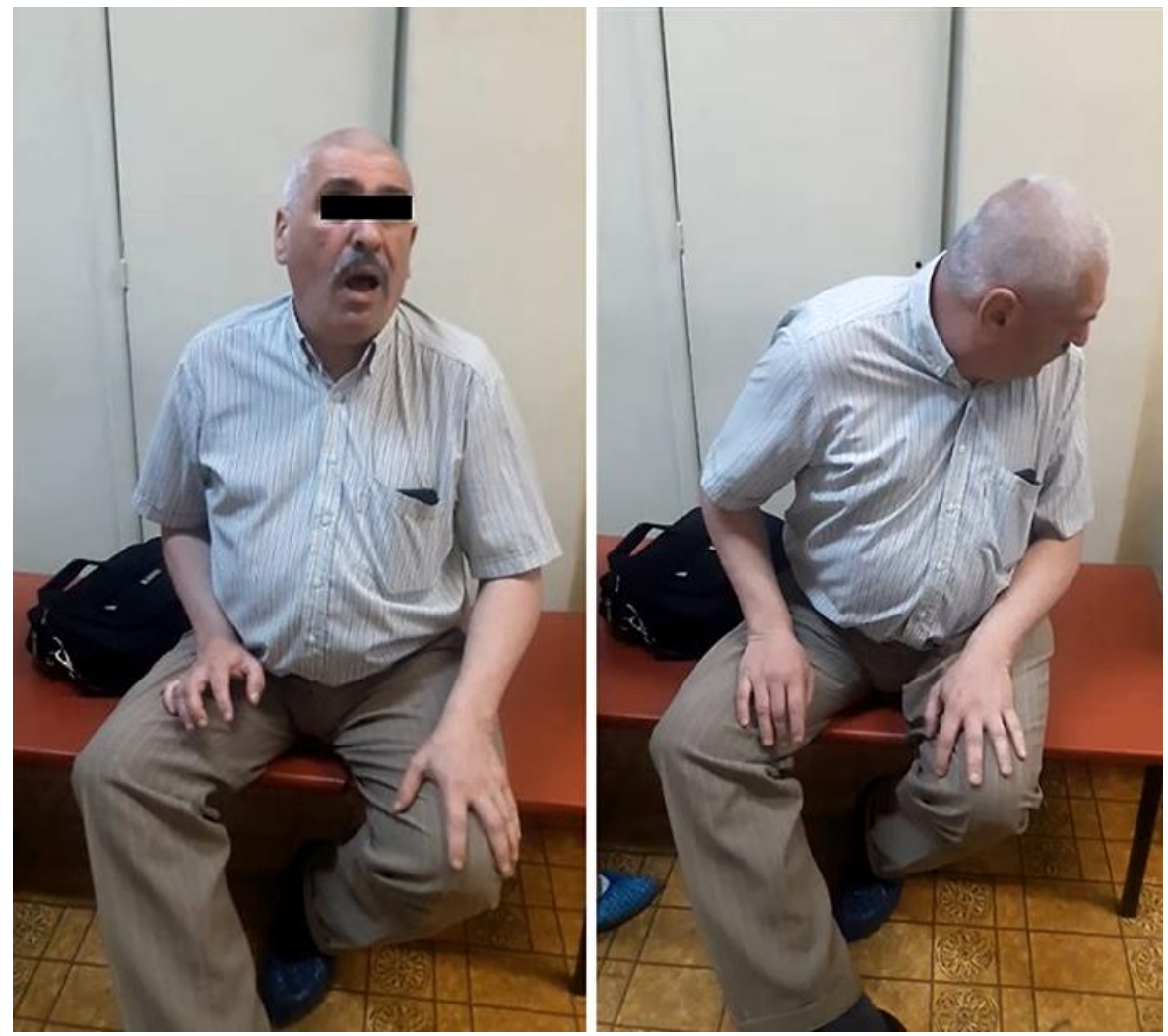

Fig. 4. Confusion after attack. 